Nigerian Journal of Environmental Sciences and Technology (NIJEST)

www.nijest.com

ISSN (Print): 2616-051X｜ＩSSN (electronic): 2616-0501

Vol 3, No. 2 October 2019, pp 245 - 255

\title{
Finite Element Application in Reservoir Deformation analysis (Pilot Phase 1)
}

\author{
Ehigiator-Irughe R. \\ Department of Geomatics, Faculty of Environmental Sciences, University of Benin, Nigeria \\ Corresponding Author: *raphael.ehigiator@uniben.edu
}

https://doi.org/10.36263/nijest.2019.02.0135

\begin{abstract}
Finite element method (FEM) is a numerical technique for solving engineering problem and mathematical physics, useful problems with complicated geometries, loading, and material properties where analytical solutions may not be obtained. Some of the complicated problems involving load is a cylindrical reservoir structure where crude oil is stored in a tank farm. This paper demonstrates the use of Finite Element Analysis in above surface cylindrical reservoir engineering structure. The reservoir which has sixteen (16) monitoring station was monitored using reflectorless Total station. This paper is a pilot model and it is hoped to be developed further in two more phases to cover the entire reservoir under study. Only two studs in the North East and South East directions were selected to test the FEM forming a triangular shade (Truss) with three elements. The $2 D$ horizontal displacement was found to be $0.02 \mathrm{~mm}$, while the vertical displacement was found to be $-0.03 \mathrm{~mm}$.
\end{abstract}

Keywords: Crude oil, Finite element, Reservoir, Stiffness matrix, Strain and stress analysis

\subsection{Introduction}

The security of civil engineering structures demands periodical monitoring. In many civil structures like bridges, vertical oil storage tanks, tunnels and dams; deformations are the most critical parameters to be monitored. Monitoring the structural deformation and dynamic response to the large variety of external loadings has great importance for maintaining structures safety and economical design of man-made structures. One of the Mathematical methods of deformation analysis is Finite Element method (FEM). Thus, the investigated deformable object must be treated as a mechanical system, which undergoes deformation according to the laws of continuum mechanics (Chrzanowski et al., 2006). This requires the causative factors (loads) of the process and the physical characteristics of the object under investigation to be included in both the design and analysis of the deformation. This is achieved by using deterministic modelling of the load-deformation relationship using finite element method (FEM) (Chrzanowski et al., 2006).

For simplicity, at this point, we assume a two-dimensional case with a single field variable $\varphi(x, y)$ to be determined at every point $\mathrm{P}(\mathrm{x}, \mathrm{y})$ such that a known governing equation (or equations) is satisfied exactly at every such point. The basic idea in the finite element method is to find the solution of a complicated problem by replacing it by a simpler one. Since the actual problem is replaced by a simpler one in finding the solution, we will be able to find only an approximate solution rather than the exact solution (Yijun, 2003). The existing mathematical tools will not be sufficient to find the exact solution (and sometimes, even an approximate solution) of most of the practical problems (Sourabh et al., 2017). Thus, in the absence of any other convenient method to find even the approximate solution of a given problem, we have to prefer the finite element method. Moreover, in the finite element method, it will often be possible to improve or refine the approximate solution by spending more computational effort (Singiresu, 2005). 


\subsection{Materials and Methods}

\subsection{Study area}

The Forcados Yokri field is located in OMLs 43 and 45 in Burutu Local Government Area of Delta State of Nigeria. It is bounded approximately by the coordinates $319453 \mathrm{mE}$ to $335236 \mathrm{mE}$ and $148355 \mathrm{mN}$ to $141626 \mathrm{mN}$.

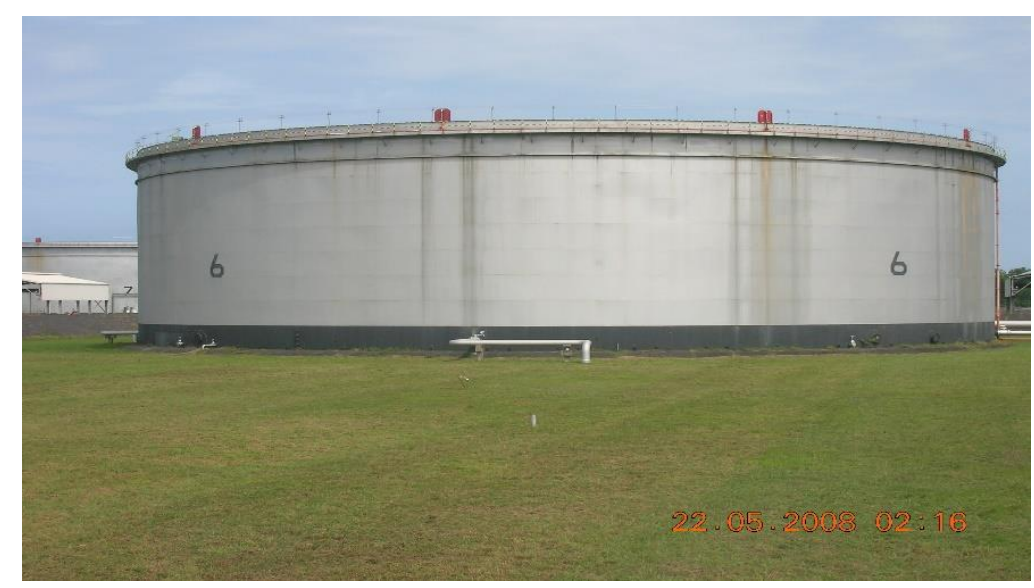

Figure 1: Reservoir no. 6

There are many severe consequences that could result from the failure of a large structure. In addition to jeopardizing public health and safety, environmental contamination and significant economic loss are also of major concern. It is for these reasons that any large deforming structure must be monitored to enable early detection of possible structural damage. Even a slight change of the object shape or changes to the surrounding area due to external factors (e.g. changes in ground water level or tectonic phenomena) no matter how insignificant they may appear could compromise the integrity of a large structure and could lead to disaster. Most deformation monitoring schemes consist of measurements made to the monitored object that are referred to several reference points (assumed to be stable). To obtain correct object point displacements (and thus deformations), the stability of the reference points must be ensured. The main conclusion from the many papers written on this topic states that every measurement made to a monitored object must be connected to stable control points. This is accomplished by creating a reference network of control points surrounding a particular structure (Ehigiator - Irughe et al., 2012).

\subsection{Methods}

An effective approach is carried out to model the structure of oil storage tank by using well-chosen discrete monitoring points located on the surface of the structure at different levels which, when situated correctly, accurately depict the characteristics of the structure.

Any movements of the monitoring point locations (and thus deformations of the structure) can be detected by maintaining the same point locations over time and by performing measurements to them at specified time intervals enabling direct point displacement comparisons (Ehigiator - Irughe et al., 2011). A common approach for this method is to place physical targets on each chosen discrete point to which measurements can be made. However, there are certain situations in which monitoring the deformations of a large structure using direct displacement measurements of targeted points is uneconomical, unsafe, inefficient, or simply impossible. Reasons for this limitation vary, but it may be as simple as placement of permanent target prisms on the structure is too difficult or costly. Figure 2 below represent monitoring stations around the reservoir under study, Figure 3 shows the circular and triangular shape of the monitored stations, Figure 4 shows the 3D view of the reservoir, while Figure 5 represent two monitored station i.e. studs 1 and 5 as well as the centre of the reservoir. 


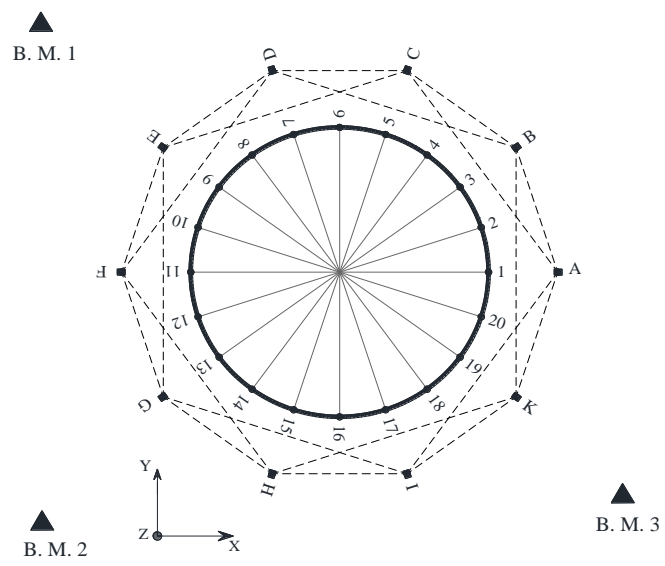

Figure 2: Design of monitoring scheme

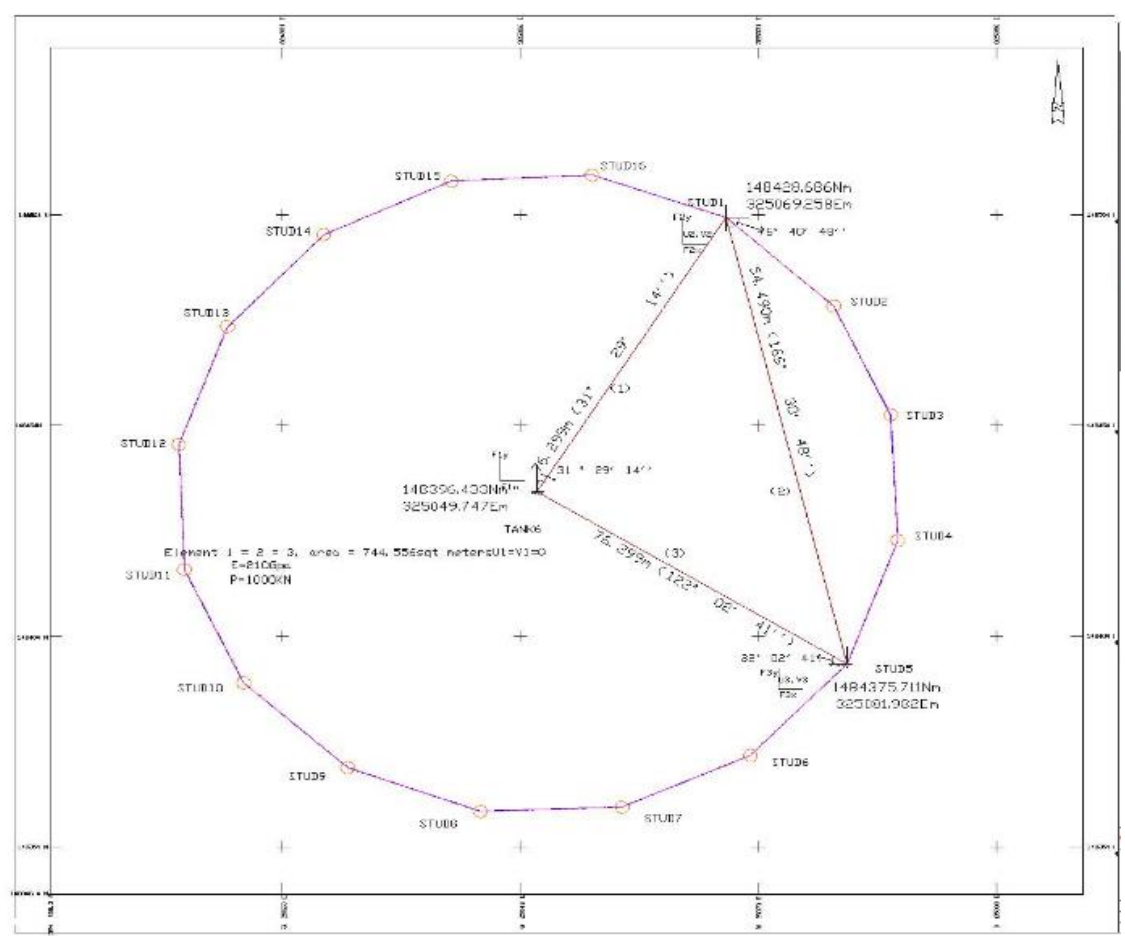

Figure 3: Circular and triangular shape of monitored stations

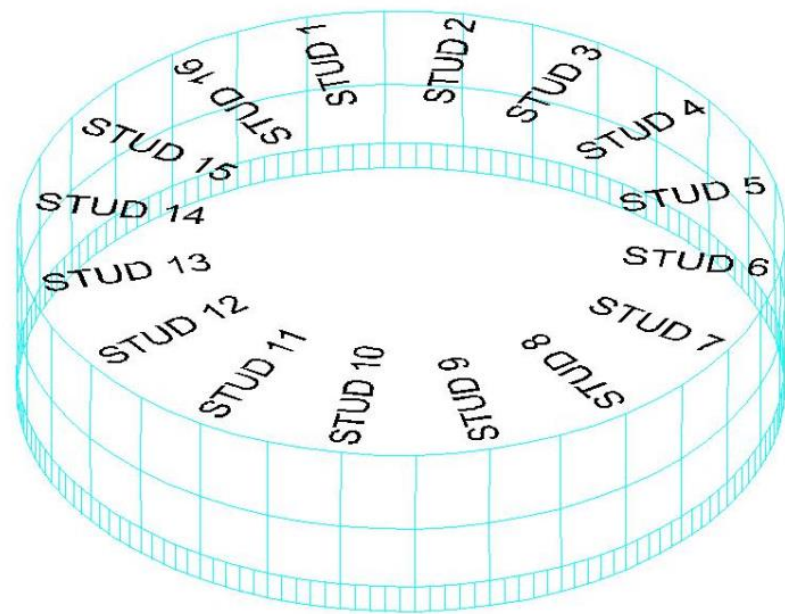

Figure 4: 3D view of reservoir 


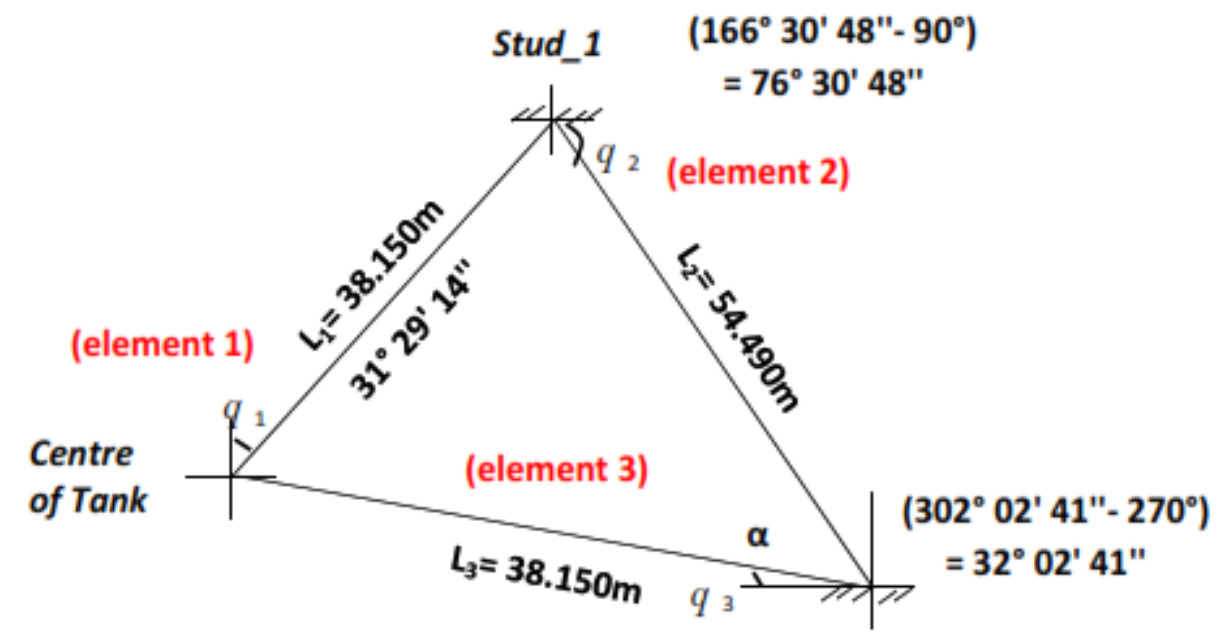

\section{Stud_5}

Figure 5: Triangular truss element for stud 1, 5 and centre of reservoir

\subsection{Results and Discussion}

Below are the reservoir parameters as presented in Tables 1 and 2. These parameters where used to determine the displacements, stress and strain of the Reservoir under study.

Table 1: The coordinates

\begin{tabular}{|l|l|l|l|}
\hline \multicolumn{2}{|l|}{ The coordinates } & \multicolumn{2}{l|}{ Derived values } \\
\hline $\mathrm{X}_{1}$ & $148396.433 \mathrm{~m}$ & $\beta_{1}$ & 52.975 \\
\hline $\mathrm{Y}_{1}$ & 325049.747 & $\beta_{2}$ & -20.722 \\
\hline $\mathrm{X}_{2}$ & 148428.686 & $\beta_{3}$ & -32.253 \\
\hline $\mathrm{Y}_{2}$ & 325069.258 & $\gamma_{1}$ & -12.724 \\
\hline $\mathrm{X}_{3}$ & 148375.711 & $\gamma_{2}$ & 32.235 \\
\hline $\mathrm{Y}_{3}$ & 325081.982 & $\gamma_{3}$ & -19.511 \\
\hline
\end{tabular}

Table 2: Reservoir properties

\begin{tabular}{|l|l|l|l|}
\hline Length & Angles & Force at node 1 and 2 & Poison $(\mu)$ \\
\hline $\mathrm{L}_{1}=38.150 \mathrm{~m}$ & $\theta_{1}=31^{0} 29^{\prime} 14^{\prime \prime}$ & $1000 \mathrm{kN}$ & 0.25 \\
\hline $\mathrm{L}_{2}=38.150 \mathrm{~m}$ & $\theta_{2}=76^{0} 30^{\prime} 48^{\prime \prime}$ & & \\
\hline $\mathrm{L}_{3}=54.490 \mathrm{~m}$ & $\theta_{3}=2^{0} 02^{\prime} 41^{\prime \prime}$ & & \\
\hline
\end{tabular}

\subsection{Determination of stiffness matrix for the elements}

The primary characteristics of a finite element are embodied in the element stiffness matrix. For a structural finite element, the stiffness matrix contains the geometric and material behaviour information that indicates the resistance of the element to deformation when subjected to loading. Such deformation may include axial, bending, shear, and torsional effects. For finite elements used in non-structural analyses, such as fluid flow and heat transfer, the term stiffness matrix is also used, since the matrix represents the resistance of the element to change when subjected to external influences. The equation for the local stiffness matrix is given by Equation (1) below.

$$
\left\{k=\frac{A E}{l}\left[\begin{array}{cccc}
l^{2} & l m & -l^{2} & -l m \\
l m & m^{2} & -l m & -m^{2} \\
-l^{2} & -l m & l^{2} & l m \\
-l m & -m^{2} & l m & m^{2}
\end{array}\right]\right\}
$$

The directional cosines 1 and $\mathrm{m}$ is given as in Equation (2): 
$\left.\begin{array}{l}\left\{l_{1}=\operatorname{Cos} \theta_{1}, m_{1}=\operatorname{Sin} \theta_{1}\right\} \\ \theta_{1}=31^{0} 29^{\prime} 14^{\prime \prime} \\ l_{1}=0.853, m=0.522\end{array}\right\}$

The strain displacement matrix $[\mathrm{B}]$ is given by:

$\left\{[B]=\frac{1}{2 A}\left[\begin{array}{cccccc}\beta_{1} & 0 & \beta_{2} & 0 & \beta_{3} & 0 \\ 0 & \gamma_{1} & 0 & \gamma_{2} & 0 & \gamma_{3} \\ \gamma_{1} & \beta_{1} & \gamma_{2} & \beta_{2} & \gamma_{3} & \beta_{3}\end{array}\right]\right\}$

where $\quad \beta_{1}=y_{2}-y_{3}, \beta_{2}=y_{3}-y_{1}, \beta_{3}=y_{1}-y_{2}$

and $\gamma_{1}=x_{2}-x_{3}, \gamma_{2}=x_{3}-x_{1}, \gamma_{3}=x_{1}-x_{2}$

or $\quad \beta_{1}=y_{23}, \beta_{2}=y_{31}, \beta_{3}=y_{12}$

and $\gamma_{1}=x_{23}, \gamma_{2}=x_{31}, \gamma_{3}=x_{12}$

The structural stiffness matrix is assembled by using the element in Equation 1 above. The local stiffness for element (1) is determined by substituting the values in Table 2 into Equation 1, to get:

$$
k_{1}=\frac{744.556 \times 210 \times 10^{9}}{38.150}\left[\begin{array}{ccccc}
u_{1} & v_{1} & u_{2} & v_{2} & \\
0.728 & 0.445 & -0.728 & -0.445 & u_{1} \\
0.445 & 0.272 & -0.445 & -0.272 & v_{1} \\
-0.728 & -0.445 & 0.728 & 0.445 & u_{2} \\
-0.445 & -0.272 & 0.445 & 0.272 & v_{2}
\end{array}\right]
$$

By similar treatment for element 2, the directional cosine and the local stiffness matrix are given thus: $l_{2}=\operatorname{Cos} \theta_{2,} m_{2}=\operatorname{Sin} \theta_{2}$

$\theta_{2}=76^{0} 30^{\prime} 48^{\prime \prime}$

$l_{2}=0.233, m=0.972$

$k_{2}=\frac{744.556 \times 210 \times 10^{9}}{54.490}\left[\begin{array}{ccccc}u_{2} & v_{2} & u_{3} & v_{3} & \\ 0.054 & 0.266 & -0.054 & -0.226 & u_{2} \\ 0.266 & 0.945 & -0.266 & -0.945 & v_{2} \\ -0.054 & -0.226 & 0.054 & 0.226 & u_{3} \\ -0.266 & -0.945 & 0.226 & 0.945 & v_{3}\end{array}\right]$

Also, by similar treatment for element 3 , the directional cosine and the local stiffness matrix, gives; $l_{3}=\operatorname{Cos} \theta_{3}, m_{3}=\operatorname{Sin} \theta_{3}$

$\theta_{3}=32^{\circ} 02^{\prime} 41^{\prime \prime}$

$l_{3}=0.848, m=0.531$ 
$k_{3}=\frac{744.556 \times 210 \times 10^{9}}{38.150}\left[\begin{array}{ccccc}u_{3} & v_{3} & u_{1} & v_{1} & \\ 0.719 & 0.450 & -0.719 & -0.450 & u_{3} \\ 0.450 & 0.281 & -0.450 & -0.281 & v_{3} \\ -0.719 & -0.450 & 0.719 & 0.450 & u_{1} \\ -0.450 & -0.281 & 0.281 & 0.281 & v_{1}\end{array}\right]$

By assembling the structural finite element thereby developing global matrix, it gives:

$$
K=K_{1}+K_{2}+K_{3}=\frac{744.556 \times 210 \times 10^{9}}{38.150 \times 38.150 \times 54.49}\left[\begin{array}{ccccccc}
u_{1} & v_{1} & u_{2} & v_{2} & u_{3} & v_{3} & \\
1.447 & 0.895 & -0.728 & -0.445 & -0.719 & -0.450 & u_{1} \\
0.895 & 0.553 & -0.445 & -0.270 & -0.450 & -0.281 & v_{1} \\
-0.728 & -0.445 & 0.782 & 0.671 & -0.054 & -0.226 & u_{2} \\
-0.445 & -0.270 & 0.671 & 1.217 & -0.226 & -0.945 & v_{2} \\
-0.719 & -0.450 & -0.054 & -0.226 & 0.773 & 0.676 & u_{3} \\
-0.450 & -0.281 & -0.226 & -0.945 & 0.676 & 1.226 & v_{3}
\end{array}\right]
$$

3.1.1. Formulation of finite element equation

$[K] \times[U]=[F]$, and applying the boundary conditions, gives:

$u_{1}=v_{1}=0$

$f_{1} x=0, f_{1} y=0$

$f_{2} x=54.069 \times 10^{3}=f_{2} y$

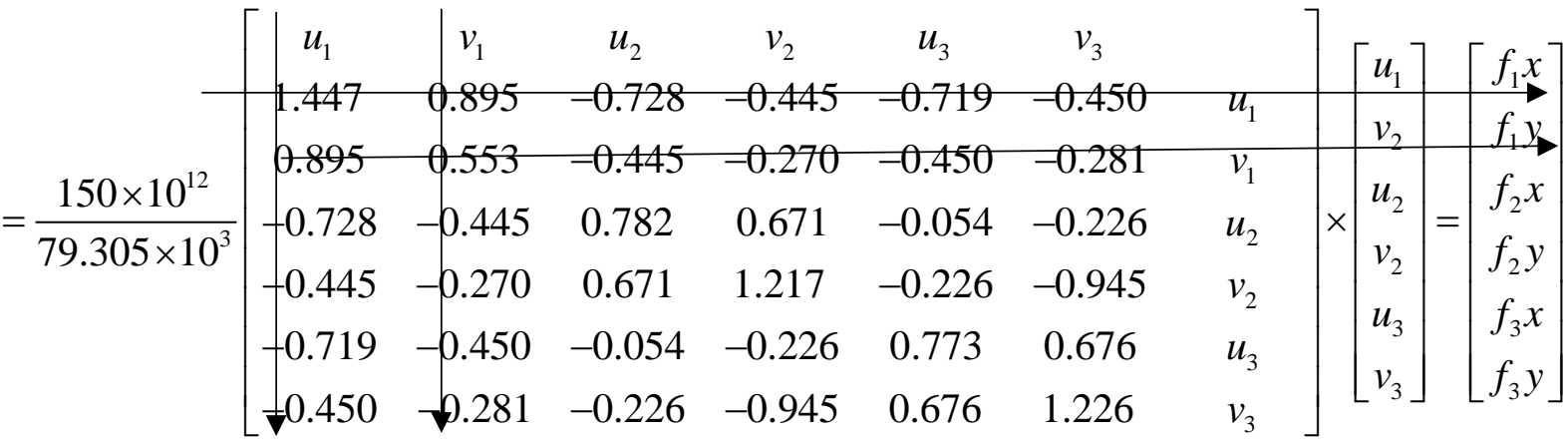

\subsection{Pressure consideration and reservoir loading}

The reservoir under study is a cylinder shape with diameter $72.3 \mathrm{~m}$ and height of $22 \mathrm{~m}$. There are 18 of such reservoirs in Forcados terminal. The circular cross section of each storage tank was divided into 16 monitoring points distributed around the tank. These monitoring points were fixed at equal intervals on the outer face of the tanks and placed at $0.5 \mathrm{~m}$ high from the tanks base. These monitoring points were established in such a way that they remain fixed throughout the period of observation.

During observations, the reservoir is first filled to a high of $3 \mathrm{~m}$ oil level, and three sets of Geomatics observations are carried out at this oil level, which are ovality, subsidence and verticality. The oil level is again filled to $10 \mathrm{~m}$, and the three sets of Geodetics observations are carried out as stated above. The reservoir is again filled to $19 \mathrm{~m}$, and the three sets of observations are conducted. For the purpose of this pilot research project, the reservoir was filled to $19 \mathrm{~m}$ oil level which is called reservoir full oil level. The pressure consideration for a reservoir at full oil level can be determined thus: 
Pr essure $=\frac{\text { Force }}{\text { SurfaceArea }}=\frac{m a}{\text { Area }}$

$\rho=\frac{m}{v}$

mass $=\rho \times v$

Vol.cylinder $=\pi r^{2} h=\pi \times 38.150 \times 19$

$=86874.55 m^{3}$

Crude oil density $=870 \mathrm{Kg} / \mathrm{m}^{3}$

Mass $=870 \times 86874.55$

$=75,580,856.798 \mathrm{~kg}$

$F=m \times a=75,580,856.798 \times 9.8=740,692,396.619 N$

Surface Area of a cylinder

$2 \pi r h+2 \pi r^{2}=2 \pi r(h+r)$

$=13,699.656 \mathrm{~m}^{2}$

Pr essure $=\frac{F}{A}=\frac{740,692,396.619 N}{13699.056}=54,068.864 \mathrm{~N}$

$=54.069 \times 10^{3} \mathrm{~N}$

The pressure value obtained will be used to determine the deformation in all other phases of subsequent studies. By substituting the pressure value and applying the boundary conditions, it becomes:

$=\frac{150 \times 10^{12}}{79.305 \times 10^{3}}\left[\begin{array}{ccccc}u_{2} & v_{2} & u_{3} & v_{3} & \\ 0.782 & 0.671 & -0.054 & -0.226 & u_{2} \\ =0.671 & 1.271 & -0.226 & -0.945 & v_{2} \\ -0.054 & -0.226 & 0.773 & 0.676 & u_{3} \\ -0.226 & -0.945 & 0.676 & 1.226 & v_{3}\end{array}\right] \times\left[\begin{array}{c}v_{2} \\ u_{2} \\ u_{3} \\ v_{3}\end{array}\right]=\left[\begin{array}{c}54.069 \\ 54.069\end{array}\right] \times 10^{3}$

Vertical displacement at nodes 2 and $3=0$

$$
\begin{aligned}
& =1891 \times 10^{6}\left[\begin{array}{cc}
0.782 & -0.054 \\
-0.054 & 0.773
\end{array}\right] \times\left[\begin{array}{l}
u_{2} \\
u_{3}
\end{array}\right]=\left[\begin{array}{l}
54.069 \\
54.069
\end{array}\right] \times 10^{3} \\
& =1891 \times 10^{3}\left[\begin{array}{cc}
0.782 & -0.054 \\
-0.054 & 0.773
\end{array}\right] \times\left[\begin{array}{l}
u_{2} \\
u_{3}
\end{array}\right]=\left[\begin{array}{l}
54.069 \\
54.069
\end{array}\right]
\end{aligned}
$$$$
=\left[\begin{array}{cc}
1478762 u_{2} & -102114 u_{3} \\
-102114 u_{2} & +14617436 u_{3}
\end{array}\right]=\left[\begin{array}{l}
54.069 \\
54.069
\end{array}\right]
$$$$
\left[\begin{array}{cc}
1478762 & -102114 \\
-102114 & 1461743
\end{array}\right]\left[\begin{array}{l}
u_{2} \\
u_{3}
\end{array}\right]=\left[\begin{array}{l}
54.069 \\
54.069
\end{array}\right]
$$$$
\left[\begin{array}{l}
u_{2} \\
u_{3}
\end{array}\right]=\left[\begin{array}{ll}
1478762 & -102114 \\
-102114 & 1461743
\end{array}\right]^{-1}\left[\begin{array}{l}
54.069 \\
54.069
\end{array}\right]
$$ 
The 1D displacement at nodes 2 and 3 are:

$\left[\begin{array}{l}u_{2} \\ u_{3}\end{array}\right]=\left[\begin{array}{l}0.3931 \\ 0.3974\end{array}\right] \times 10^{-4}$

\subsection{Strain analysis}

When an object is subjected to external force, initially at equilibrium condition, the deformation effect is negligible. However, with a gradual increase in the magnitude of the applied load, the dimensions of the object will be altered, due to deformation. The ratio of change in the dimension due to deformation of the object to its original dimension is called strain. Strain is defined as the force tending to pull or stretch an object to an extreme or damaging degree. The finite element model for strain analysis is given as:

$$
\left[\begin{array}{l}
\xi_{x} \\
\xi_{y} \\
\xi_{x y}
\end{array}\right]=[B]\left[\begin{array}{l}
u_{1} \\
v_{1} \\
u_{2} \\
v_{2} \\
u_{3} \\
v_{3}
\end{array}\right]
$$

where:

$[\mathrm{B}]$ is as defined in equation $(1-3), u_{1}, v_{1}, u_{2}, v_{2}, u_{3}, v_{3}$ are the deformation at nodes 1,2 and 3 respectively.

By substituting the derived values in Table 1 into Equation (3), it gives:

$$
\left[\begin{array}{l}
\xi_{x} \\
\xi_{y} \\
\xi_{x y}
\end{array}\right]=\frac{1}{2 \times 744.560}\left[\begin{array}{cccccc}
-12.725 & 0 & 32.235 & 0 & -19.511 & 0 \\
0 & 52.975 & 0 & -20.722 & 0 & -32.253 \\
52.975 & -12.725 & -20.722 & 32.235 & -32.253 & -19.511
\end{array}\right]\left[\begin{array}{l}
0 \\
0 \\
39.31 \\
0 \\
39.74 \\
0
\end{array}\right] \times 10^{-6}
$$

The strain is given as:

$$
\left[\begin{array}{l}
\xi_{x} \\
\xi_{y} \\
\xi_{x y}
\end{array}\right]=\left[\begin{array}{c}
0.0330 \\
0 \\
-0.1408
\end{array}\right] \times 10^{-5}
$$

\subsection{Stress expression}

The intensity of the resisting force offered by the intermolecular bonding of the object per unit area towards the load applied before the failure of the object is called as stress. This is also defined as the force per cross - sectional area and the modulus of elasticity for this material under study is given as; $210 G p a=210 \times 1000=210,000 \mathrm{~N} / \mathrm{mm}^{2}$

$$
\left[\begin{array}{c}
\sigma_{x} \\
\sigma_{y} \\
\sigma_{x y}
\end{array}\right]=D\left[\begin{array}{l}
\xi_{x} \\
\xi_{y} \\
\xi_{x y}
\end{array}\right]=\frac{E}{1-v^{2}}\left[\begin{array}{lll}
1 & v & 0 \\
v & 1 & 0 \\
0 & 0 & 1
\end{array}\right]\left[\begin{array}{l}
\xi_{x} \\
\xi_{y} \\
\xi_{x y}
\end{array}\right]
$$


By substituting into Equation 4, it becomes:

$$
\begin{aligned}
& \frac{210,000}{1-(0.25)^{2}}\left[\begin{array}{ccc}
1 & 0.25 & 0 \\
0.25 & 1 & 0 \\
0 & 0 & \left(\frac{1-0.25}{2}\right)
\end{array}\right]\left[\begin{array}{l}
0.0330 \\
0 \\
-0.1408
\end{array}\right] \times 10^{-5} \\
& 224,000 *\left[\begin{array}{ccc}
1 & 0.25 & 0 \\
0.25 & 1 & 0 \\
0 & 0 & 0.375
\end{array}\right]\left[\begin{array}{l}
0.1178 \\
0 \\
0.5035
\end{array}\right] \times 10^{-5} \\
& {\left[\begin{array}{c}
\sigma_{x} \\
\sigma_{y} \\
\sigma_{x y}
\end{array}\right]=\left[\begin{array}{c}
0.0740 \\
0.0185 \\
-0.1183
\end{array}\right]}
\end{aligned}
$$

The principle of stress is given as:

$$
\begin{aligned}
& \left.\sigma_{1,2}=\frac{\sigma_{x}+\sigma_{y}}{2} \pm \sqrt{\left(\frac{\sigma_{x}-\sigma_{y}}{2}\right)^{2}+\sigma_{x y}^{2}}\right\} \\
& =\frac{0.0740+0.0185}{2} \pm \sqrt{\left(\frac{0.0740-0.0185}{2}\right)^{2}+(-0.1183)^{2}} \\
& \sigma_{1,2}=0.046 \pm \sqrt{(0.028)^{2}+(-0.1183)^{2}} \\
& \sqrt{7.8 \times 10^{-4}+1.392 \times 10^{-2}} \\
& =0.121 \\
& \sigma_{1,2}=0.046 \pm 0.121 \\
& \sigma_{1,2}=0.046+0.121=0.167 \\
& \text { or } \\
& \sigma_{1,2}=0.046-0.121=-0.075
\end{aligned}
$$

\subsection{Determination of $2 D$ horizontal and vertical displacement}

The horizontal and vertical displacement can the determined by assuming the following boundary conditions. 
$f_{1 x}=f_{1 y}=0, f_{2 x}=f_{2 y}=f_{3 x}=f_{3 y}=54.069 \times 10^{3} \mathrm{~N}$

$=\frac{150 \times 10^{12}}{79.305 \times 10^{3}}\left[\begin{array}{ccccccc}u_{1} & v_{1} & u_{2} & v_{2} & u_{3} & v_{3} \\ 1.447 & 0.895 & -0.728 & -0.445 & -0.719 & -0.450 & u_{1} \\ 0.895 & 0.553 & -0.445 & -0.270 & -0.450 & -0.281 & v_{1} \\ -0.728 & -0.445 & 0.782 & 0.671 & -0.054 & -0.226 & u_{2} \\ -0.445 & -0.270 & 0.671 & 1.217 & -0.226 & -0.945 & v_{2} \\ -0.719 & -0.450 & -0.054 & -0.226 & 0.773 & 0.676 & u_{3} \\ -0.450 & -0.281 & -0.226 & -0.945 & 0.676 & 1.226 & v_{3}\end{array}\right] *\left[\begin{array}{l}u_{1} \\ v_{2} \\ u_{2} \\ v_{2} \\ u_{3} \\ v_{3}\end{array}\right]=\left[\begin{array}{l}f_{1} x \\ f_{1} y \\ f_{2} x \\ f_{2} y \\ f_{3} x \\ f_{3} y\end{array}\right]$

$=\frac{150 \times 10^{12}}{79.305 \times 10^{3}}\left[\begin{array}{rrrr}0.782 & 0.671 & -0.054 & -0.226 \\ 0.671 & 1.217 & -0.226 & -0.945 \\ -0.054 & -0.226 & 0.773 & 0.676 \\ -0.226 & -0.945 & 0.676 & 1.226\end{array}\right] \times\left[\begin{array}{l}u_{2} \\ v_{2} \\ u_{3} \\ v_{3}\end{array}\right]=\left[\begin{array}{l}54.069 \\ 54.069 \\ 54.069 \\ 54.069\end{array}\right] \times 10^{3}$

$\left[\begin{array}{l}u_{2} \\ v_{2} \\ u_{3} \\ v_{3}\end{array}\right]=\left(\frac{150 \times 10^{12}}{79.305 \times 10^{3}}\left[\begin{array}{rrrr}0.782 & 0.671 & -0.054 & -0.226 \\ 0.671 & 1.217 & -0.226 & -0.945 \\ -0.054 & -0.226 & 0.773 & 0.676 \\ -0.226 & -0.945 & 0.676 & 1.226\end{array}\right]\right)^{-1}\left[\begin{array}{l}54.069 \\ 54.069 \\ 54.069 \\ 54.069\end{array}\right] \times 10^{3}$

$\left[\begin{array}{l}u_{2} \\ v_{2} \\ u_{3} \\ v_{3}\end{array}\right]=\left(1891 \times 10^{3}\left[\begin{array}{rrrr}0.782 & 0.671 & -0.054 & -0.226 \\ 0.671 & 1.217 & -0.226 & -0.945 \\ -0.054 & -0.226 & 0.773 & 0.676 \\ -0.226 & -0.945 & 0.676 & 1.226\end{array}\right]\right)^{-1}\left[\begin{array}{l}54.069 \\ 54.069 \\ 54.069 \\ 54.069\end{array}\right]$

The horizontal and the vertical displacement was found to be:

$\left[\begin{array}{l}u_{2} \\ v_{2} \\ u_{3} \\ v_{3}\end{array}\right]=\left[\begin{array}{c}0.0203 \\ -0.0332 \\ 0.0209 \\ -0.0333\end{array}\right]$

\subsection{Conclusion}

This research is a pilot project for a reservoir with $72.3 \mathrm{~m}$ diameter and height of $22 \mathrm{~m}$ surrounded with 16 studs serving as monitoring stations. In this study, only two studs, i.e. stud 1 and 5 were used, and the centre of the reservoir with $38.15 \mathrm{~m}$ as the radius. The reservoir is to be divided into three parts, with each part studied separately. The results presented here are for phase 1 i.e. the first part. The results for the second and third phases will be presented in subsequent studies. Based on the results presented, the following highlights are summarized:

1. It is possible to use finite element method to obtain the deformation of large surface reservoirs

2. Monitoring techniques of large circular oil storage tanks can provide valuable deformation data 
3. The suggested technique of analysis for the structural deformation observations can be used to identify and determine the values of deformation for any structure for one epoch of observation

4. The horizontal displacement at studs one and five are almost the same with values of $0.0203 \mathrm{~mm}$ and $0.0209 \mathrm{~mm}$ respectively

5. The vertical displacements for the same points are $-0.0332 \mathrm{~mm}$ and $-0.0333 \mathrm{~mm}$. This indicates that the vertical displacement is downward, which may represent subsidence or settlement of the foundation at full load.

\section{References}

Ehigiator - Irughe, R., Ashraf, A. A. B., Ehiorobo, J. O. and Ehigiator, M. O. (2011). Modification of Geodetic Methods for Determining the Monitoring Station Coordinates on the Surface of Cylindrical Oil Storage Tank. Research Journal of Engineering and Applied Sciences (RJEAS), 1(1), pp. 58 - 63.

Ehigiator-Irughe, R., Ehiorobo, J. O., Ashraf, A. B. and. Ehigiator, M. O. (2012). Determination of the Ovality of Crude Oil Storage Tanks using Least Squares. Advanced Materials Research, 367, pp. 475-483, Trans Tech Publications, Switzerland. www.scientific.net/AMR.367.475

Yijun, L. (2003): Lecture note: Introduction to the Finite Element Method, CEA Research Laboratory, Department of Mechanical Engineering, University of Cincinnati, USA.

Chrzanowski, A. and Wilkins, R. (2006) Accuracy Evaluation of Geodetic Monitoring of Deformations in Large Open Pit Mines. Proceedings of the 3rd IAG Symposium on Geodesy for Geotechnical and Structural Engineering and 12-th FIG Symposium on Deformation Measurements.

Singiresu, S. Rao (2004). The finite element method in Engineering Fourth Edition

Sourabh, V., Jain, K. K. and Dave, R. K. (2017). Finite Element Analysis of Disc Brake Rotor for Different Material. International Journal of Information Technology \& Mechanical Engineering IJITME, 3(8), pp. 1-14.

\section{Cite this article as:}

Ehigiator-Irughe, R. (2019). Finite Element Application in Reservoir Deformation analysis (Pilot Phase 1). Nigerian Journal of Environmental Sciences and Technology, 3(2), pp. 245-255. https://doi.org/10.36263/nijest.2019.02.0135 